Şırnak Üniversitesi

Ilahiyat Fakültesi Dergisi

Sayı 26 Haziran 2021

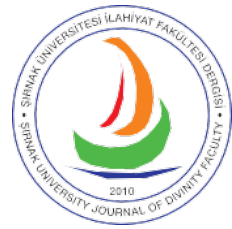

Şırnak University

Journal of Divinity Faculty

Issue 26 June 2021

\title{
Hegel'in Protestan Devleti
}

Hegel's Protestant State

\section{Ceyhan IŞIK}

Dr.

PhD, Independent Researcher

Adana, Turkey

ceyhan011980@gmail.com

https://orcid.org/0000-0002-5067-1799

\section{Makale Bilgisi / Article Information}

Makale Türü / Article Types: Araştırma Makalesi / Research Article

Geliş Tarihi / Received: 23 Şubat / February 2021

Kabul Tarihi / Accepted: 13 Nisan / April 2021

Yayın Tarihi / Published: 15 Haziran / June 2021

Sayı / Issue: 26 Sayfa / Pages: 69-90

Atıf / Cite as: Işık, Ceyhan. "Hegel'in Protestan Devleti [Hegel's Protestant State]". Şırnak Üniversitesi İlahiyat Fakültesi Dergisi - Şırnak University Journal of Divinity Faculty 26 (June 2021), 69-90. https://doi.org/10.35415/sirnakifd.885210

Etik Beyanı / Ethics Declaration: Bu makalede bilimsel araştırma ve yayın etiği ilkelerine riayet edilmiştir. Makale etik izin gerektirmeyen bir çalışma olup en az iki hakem tarafından incelenmiş ve intihal içermediği teyit edilmiştir. / In this article, the principles of scientific research and publication ethics are respected. The article is a study that does not require ethical permission. It has been reviewed by at least two referees and was confirmed that it did not contain plagiarism.

Copyright (C) Published by Şırnak Üniversitesi, İlahiyat Fakültesi / Şırnak, Türkiye (Şırnak University, Faculty of Divinity, Şırnak, 73000 Turkey). 


\section{Özet}

Din-devlet ilişkisinin yanı sıra din ve siyasette yenileşme de ilgi çeken konular arasında yer almaktadır. Bazı önemli dönemler ve dönüm noktaları bu ilişkileri şekillendirmesi açısından önemlidir. Eski İran devlet geleneği, Yunan demokrasisi, VIII. Henry İngiltere'si ve Rus Ekim 1917 Bolşevik Devrimi gibi. Fransız devrimi sonrası Avrupa'da ciddi bir biçimde yeni tarz siyasetin ne olması gerektiği ile ilgili ciddi sorun oluştu. Bu sorunların bir kısmı salt politik idi. Bunun yanı sıra din, kilise, gelenek, yenilik, muhafazakârlık, ekonomi, sınıfsal çatışma ve felsefe ile ilgi olan yeni sorunlar ortaya çıtı. Immanuel Kant, Edmund Burke, Friedrich Heinrich Jacobi, Emmanuel-Joseph Sieyès, Johann Gottlieb Fichte, Karl Marks, Friedrich Engels gibi düşünürler bu tarz sorunlarla ilgilendiler. Bu konuları ele alan en önemli bir düşünür de Georg Wilhelm Friedrich Hegel'dir. Hegel politikayı teolojiden bağımsız bir şekilde ele almamaktadır. Dolayısıyla o, devletin özü, tarihteki bireysel devletler, politik kurumlar, politik devrimler ve devlet şekilleri gibi konulara teolojik-politik bir açıdan yaklaşır. Fransız devrimi sonrası oluşan yeni politik durumu Martin Luther'in Protestan Hristiyanlığ ile ilintileyerek modern bir Protestan devlet formülasyonu oluşturdu. Bu noktada Hegel'in iki önemli unsuru devreye soktuğuna dikkat çekilmelidir: Törellik ve tin-hakikat birliği olarak Protestan ilke. Bu makalenin de temel amacı Hegel'in Protestan devletini bu iki olgu etrafında incelemektir. Hegel için törellik bir Protestan icadıdır. Protestan icadı olan törellikte objektiflik ve sübjektiflik; hukuk ve ahlak uyum halindedir. Hegel bununla romantiklerin iddiası olan Protestanlıktaki otorite yoksunluğunu da boşa çıkarmak istiyordu: Eğer Katoliklikte somut otorite papalık ise bu Protestanlıkta törelliktir. Protestan ilke olan tin-hakikat birliği de -törellikte olduğu gibi- ikilemleri aşan bir olgudur. Hegel, Protestan devleti Protestan ilke olan tin-hakikat birliği üzerine inşa eder. Hegel her şeyden önce Katolikliğin Tanrı'yı dışsal olarak algılayıp bilmesine karşın Protestanlığın Tanrı'yı içsel olarak bildiği görüşünü savunur. Buna göre Protestanların ve Katoliklerin Tanrı'yı farklı biçimlerde algılama tarzları sonuçta Protestanlığın ve Katolikliğin birçok inanç, ibadet ve politikasını şekillendirmektedir. Bu nedenden Luther'in reformu siyasi konularda avantajlı geçişler sağlamaktadır. Makalenin önemli yönlerini teşkil eden bu yönlerin yanı sıra, varılan bazı düşüncelerin de öneminin altınının çizilmesi gerekir. Bizce bunların başında şu çıkarsama gelmektedir: Din, devletin temeli olmanın yanı sıra devlet reformunun da temelidir. Netice itibariyle dinsel reformunu tamamlamamış ulusların politik reformları yarım kalmaya mahkûmdur. Hegel; din, devlet, reform, zamansallık arasında bir uyumu şart koşmaktadır. Metot olarak makale; yapısal, karşılaştırmalı ve sonuç çıkarmalı yöntemler kullanmaktadır. Protestan devlet; diyalektik, bilgi-eylem birliği, törellik, dinsel reform, Protestan ilke ve Katoliklik karşıtlığı etrafında yapılandırılmaktadır. Dolayısıyla bu makalede de kıyaslamalı anlatım elden geldiğince kullanılmaktadır. Çalışmada elde edilen sonuçlar da Katoliklik ile kıyaslamalı olarak yapılandırılmaktadır: İçsel-tinsel Protestan devlet- dışsal Katolik devlet, laik Protestan devlet laik olmayan Katolik devlet, ulusal Protestan Devlet-Katolik imparatorluk, güvenilir Protestan devlet-güvensiz Katolik devlet. Anahtar Kelimeler: Felsefe Tarihi, Protestan İlke, Reform, Katoliklik, Törellik, Laiklik. 


\section{Summary}

In addition to the religion-state relationship, religious and political reform is also among the interesting topics. Some important periods and turning points such as the ancient Iranian state tradition, Greek democracy, England in the time of Henry VIII and the Russian Bolshevik Revolution of October 1917 are critical in shaping these relationships. After the French revolution, there was a serious problem about what the new style of politics should be in Europe. Some of these problems were purely political. In addition, new problems arose related to religion, church, tradition, reform, conservatism, economy, class conflict and philosophy. Philosophers such as Immanuel Kant, Edmund Burke, Friedrich Heinrich Jacobi, Emmanuel-Joseph Sieyès, Johann Gottlieb Fichte, Karl Marx, Friedrich Engels were interested in such problems. One of the most important philosophers dealing with these issues is Georg Wilhelm Friedrich Hegel. Hegel does not deal with politics independent of theology. Therefore, he approaches issues such as the essence of the state, individual states, political institutions, political revolutions, and forms of state in history from a theologicalpolitical perspective. He created a modern Protestant state formulation by linking the new political situation that emerged after the French revolution with Martin Luther's Protestant Christianity. At this point, it should be noted that Hegel put two important elements into use: The ethical life and the Protestant principle as the unity of spirit and truth. The main purpose of this article is to examine Hegel's Protestant state around these two facts. For Hegel, ethical life is a Protestant invention. Here, objectivity with subjectivity; law with morality are in harmony. With this, Hegel also wanted to negate the lack of authority in Protestantism claimed by romantics. If the concrete authority in Catholicism is the papacy, it is then ethical life in Protestantism. The Protestant principle, the unity of spirit and truth, is a fact that supersedes dilemmas, as in the case of morality. Hegel constructs the Protestant state on the Protestant principle of unity of spirit and truth. First of all, he thinks that Protestantism knows God internally, although Catholicism perceives and knows God externally. Accordingly, the way Protestants and Catholics perceive God in different ways ultimately shapes many beliefs, practices, and policies of Protestantism and Catholicism. For this reason, Luther's reform provides advantageous cases in political matters. In addition to these aspects, which constitute the critical facets of the article, the importance of some ideas should also be underlined. In our opinion, the following inference is the most meaningful: Religion is the basis of state reform as well as being the foundation of the state. As a result, the political reforms of nations that have not completed their religious reform are doomed to be left unfinished. Hegel stipulates a harmony among religion, state, reform and temporality. This article uses structural, comparative and inference methods. The Protestant state is structured in the context of dialectics, unity of theory and practice, morality, religious reform, Protestant principle and anti-Catholicism. Hegel evaluates the Protestant state, which he founded on the basis of the Protestant principle, by comparing it with Catholicism and its state. Therefore, we use comparative explanations as much as possible in this article. The results obtained from the study are also formed in comparison to Catholicism: İnternalspiritual Protestant state vs. external Catholic state, secular Protestant state vs. non secular Catholic state, national Protestant State vs. Catholic empire, reliable Protestant state vs. insecure Catholic state.

Keywords: History of Philosophy, Protestant Principle, Reform, Catholicity, Ethical Life, Laicity. 
Giriş

Hegel hayatta iken Alman birliği henüz sağlanmamıştı ve çeşitli politik oluşumlar ve düşünceler Almanya'da hâkimdi. Hegel'in ilgisini çeken ise yalnızca bu politik durum değildi ayrıca dinsel durumdu. Franz Rosenzweig Hegel'in Fransa'yı değil, Avusturya'yı Protestan Almanya için alternatif olarak algıladığını belirtir. Hatta Rosenzweig onun Avusturya'nın güney Almanya'nın yanı sıra tüm Almanya'da hüküm sürebileceği konusunda endişe ettiğini ekler. ${ }^{1}$ Martin Luther Almanya'yı dil yoluyla birleştirmişti, ancak Protestanlık yoluyla bölmüştü. Hegel'in ifade ettiği gibi Luther'in reform çabası ilk etapta Katoliklik dünya çerçevesindeydi², ancak bu süreç bölünme ile sonuçlandı. Netice itibariyle Hegel Protestanlığı yalnızca dinsel bir olgu olarak algılamamış, onu ayrıca kültürel ve politik bir olgu olarak görmüştür ve bu bağlamda Protestanlığı Kuzey İlkesi olarak tanımlamıştır. Kuzey İlkesinin şiarı tin ve hakikatin birliğidir ve bu ilke tarihteki en yüce kültürel forma sahiptir. ${ }^{3}$ Bunun yanı sıra Hegel, Johann Gottlieb Fichte ile benzerliğe sahip olacak bir biçimde, şiarı ilahilik-beşerilik birliği olan Hristiyan Cermen ilkesinde de bahseder. ${ }^{4} \mathrm{~Hz}$. Isa Tanrı ve beşer olarak hem ilahilik hem de beşerilik doğalarına sahiptir. Bu sebepten ilahilik ve beşerilik birbirleriyle uyum halindedir. Bu iki doğa birbirleriyle salt bir biçimde aynı değildirler. Farklı mevcudiyetler olarak birbirleriyle birlik halindedirler. Dolayısıyla birlik kendisini çokluk yoluyla gerçekleştirmektedir. Hegel'in ilahilik-beşerilik birliği olarak gördüğü Hristiyan-Cermen ilkesi aslında tin-hakikat birliğini temsil eden Protestan ilke ile yakından ilintilidir. Her iki ilke de Hegel'in Hristiyan delili olarak adlandırdığ delil ile ilgilidir. Doğa ile ilintili olan kozmolojik ve teleolojik delillerin aksine ontolojik delil insan tininden çıan yegâne delildir. Hegel ontolojik delili teslis ve hulul ile ilişkilendirir: Nasıl ki baba çocuğu kapsıyorsa Tanrı kavramı da onun mevcudiyetini zorunlu bir biçimde içerir. Neticede Tanrı kendini insan yaptı. Tanrı ve insan farklılıklarıyla birlikte birlik halindedir: 5

1 Franz Rosenzweig, Hegel und der Staat, Herausgegeben von Frank Lachmann, Mit einem Nachwort von Axel Honneth, (Berlin: Suhrkamp Verlag, 2010), 341-342.

2 Georg Wilhelm Friedrich Hegel, Vorlesungen über die Philosophie der Geschichte. Werke 12, Hrsg. Von Moldenhauer and K. M. Michel, (Frankfurt: Suhrkamp, 1986), 497.

3 Glauben und Wissen oder die Reflexionsphilosophie der Subjektivität in der Vollständigkeit ihrer Formen als Kantische, Jacobische und Fichtesche Philosophie, Jenaer Schriften, Werke 2, (Frankfurt: Suhrkamp, 1986), 289.

4 Johann Gottlieb Fichte, Die Anweisung zum seligen Leben, oder auch die Religionslehre, Johann Gottlieb Fichtes sämmtliche Werke. Band 5, (Berlin: Verlag von L. Heimann: 1845/1846), 108-109, 567-573.

5 Hegel, Vorlesungen über die Philosophie der Religion II Vorlesungen über die Beweise vom Dasein Gottes, Werke 17, (Frankfurt: Suhrkamp, 1086), 252; Grundlinien der Philosophie des Recht oder Naturrecht und Staatswissenschaft im 
Tablo 1: Genel Hegel Felsefesi

İlk dur son. ${ }^{6}$

\begin{tabular}{|c|c|c|c|}
\hline Hristiyanlık & Tanrı & İsa & Kutsal ruh (tin) \\
\hline Hristiyanlık & Baba & Oğul & Kutsal ruh \\
\hline Ontolojik delil & Kavram & Varlık & Birlik $^{\text {Tanrı }}$ \\
\hline Tin felsefesi & $\begin{array}{c}\text { dir } \\
\text { (gerçekleşme) }\end{array}$ & Mutlak tin. $^{7}$ \\
\hline Din & Sonsuz ruh & Sonlu ruh -insan- & Birlik \\
\hline Hegel sistemi & Mantık & Doğa & Tin \\
\hline Hristiyan-Cermen ilke & İlahilik & Beşerilik & Uyum \\
\hline
\end{tabular}

$\mathrm{Bu}$ formülasyonlar Hegel'in mantıksal diyalektik formül kavramsallaştırmaları ile uyumludurlar:

Tablo 2: Hegel'in Diyalektiği

\begin{tabular}{|c|c|c|}
\hline Tez & Antitez & Sentez \\
\hline Süje & Obje & Mutlak \\
\hline Form & İçerik & Birlik \\
\hline Kendinde & Kendisi için & Kendisiyle \\
\hline Dynamis & Energeia & Birlik \\
\hline Bilkuvve & Bilfiil & Dolayımlama \\
\hline Dolayımsılılk & Kaldırıp-içerme & Birlik \\
\hline İlineksellik & Zorunluluk & \\
\hline
\end{tabular}

Grundrisse, Mit Hegels eigenhändigen Notizen und den mündlichen Zusätzen, Werke 7, 2. Aufl., Frankfurt, Suhrkamp, 1989), 74; Vorlesungen über die Geschichte der Philosophie I, Werke 18, (Frankfurt am Main, Suhrkamp, 1986), 39; Enzyklopädie der philosophischen Wissenschaften im Grundrisse 1830, Erster Teil, Die Philosophie des Geistes Mit den mündlichen Zusätzen, Werke, Frankfurt: Suhrkamp, 1989, 179; Enzyklopädie der philosophischen Wissenschaften im Grundrisse 1830, Dritter Teil, Die Philosophie des Geistes Mit den mündlichen Zusätzen, Werke 10, Frankfurt: Suhrkamp, 1989), 38; Naturrecht und Staatswissenschaft nach der Vorlesungsnachschrift von C. G. Homeyer 1818/1819, Georg Wilhelm Friedrich Hegel Vorlesungen über Rechtsphilosophie 1818-1831, Edition und Kommentar in sechs Bänden von Karl-Heinz Ilting, Erster Band, Stuttgart-Bad Cannstatt, frommann-holzboog, 1973), 237-238.

6 Hegel, Wissenschaft der Logik I, Werke 5, (Frankfurt: Suhrkamp. 1986), 70. Almanca İngilizce gibi özne ile yüklem arasına yardımcı fiil gelir ki bu Almancada "ist" iken İngilizcede ise "is" olmaktadır. "İlk sondur" cümlesine ona göre yer verilmiştir.

7 Burada da Almanca cümle yapısı Türkçe cümle yapısına göre düzenlenmiştir. 


\begin{tabular}{|c|c|c|}
\hline Soyut & Somut & Birlik \\
\hline İmkân & Gerçeklik & Birlik \\
\hline İçsellik & Dişsallık & Birlik \\
\hline
\end{tabular}

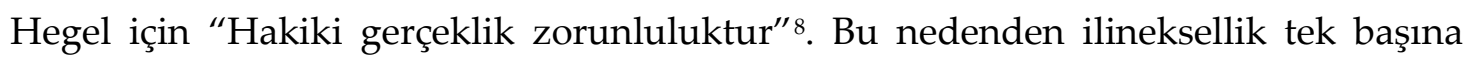
gerçeklik değildir zira Tanrı'nın varlığı dâhil her şey imkân dâhilindedir. Hegel Türk Sultanı Papa bile olabilir der. ${ }^{9}$ Neticede hakikat totallik, farklı kavramların birliği olmaktadır. Hegel kendi zamanında içsellik ve dışsallık; sübjektiflik ve objektif arasındaki birliği karşılamadığından Protestanlıktan Katolikliğe geçen kişilerden bahseder. Hug Bar Nisbet'in belirttiği gibi Karl Wilhelm Friedrich Schlegel ve Friedrich Leopold Graf zu Stolberg

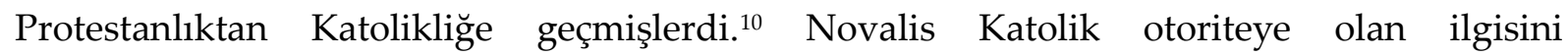
gizlememişti. ${ }^{11}$ Möller'in Hegel'e yolladığ 14 Kasım 1804 tarihli mektuba dayanan Clark Butler Hegel'in Katolikliğe geçişi gündemine aldığını ileri sürer. Ancak sözü edilen mektuba baktığımızda Möller'in kendi Katolikliğe geçişi konusunda Hegel ile fikir alışverişinde bulunduğunu görmekteyiz. Yani bu mektubun konusu Hegel'in Katolikliğe geçişi ile ilgili değildir. Yine Butler'a göre Hegel'in flört ettiği Nanette Endel, Hegel'in Katolikliği gündeme getirmesinde yer alan nedenler arasında yer almaktayd1. ${ }^{12}$ Hegel uzmanları Hegel'in Katolikliğe geçiş komsundaki iddiaları aslında şimdiye kadar ciddiye almadılar. Konu hakkında daha fazla delil ve ikna edici yorumların getirilmesi gerekmektedir. Şimdi yine Möller'in mektuba geri gelmek istiyoruz. Bu mektupta Möller Hegel'e Augustine okumasını tavsiye eder. Daha ilginç olanı ise Möller'in Augustine'i platonik Hristiyanlık ile ilişkilendirmesidir. ${ }^{13}$ Möller böyle yaparak muhtemelen Hegel'in dikkatini çekmeye çalışmaktayd $1 .{ }^{14} \mathrm{O}$, Hegel'in platonik idealizme karşı olan ilgisini biliyor olmalıydı. O dönem

8 Hegel, Philosophie des Rechts Nach der Vorlesungsnachschrift H.G. Hotho 1822/1823, Georg Wilhelm Friedrich Hegel Vorlesungen über Rechtsphilosophie 1818-1831, Edition und Kommentar in sechs Bänden von Karl-Heinz Ilting, Dritter Band, Stuttgart-Bad Cannstatt, frommann-holzboog, 1974), 270.

9 Enzyklopädie der philosophischen Wissenschaften im Grundrisse 1830 I, 283.

10 Elements of the Philosophy of Right, edited by Allen W Wood; translated by H. .B Nisbet, (Cambridge: Cambridge University Press, 1991), 435.

11 Novalis, Die Christenheit oder Europa. Ein Fragment, Novalis Schriften, Ludwig Tieck, Friedrich Schlegel (Hrsg.), Bd. 1., (Berlin: Reimer, 1826), 187-208.

12 Hegel, The Letters, Translated by Clark Butler and Christiane Seiler with commentary by Clark Butler, Bloomington: Indiana University Press, 1984), 8. Hegel'in Katoliklik ile olan kişisel ilişkileri için ayrıca bk. (Stepelevich: 673-678).

13 Hegel, Briefe von und an Hegel, Band I, 1785-1812, (Hamburg: Felix Meiner Verlag, 1969), 87.

14 Vorlesungen über die Geschichte der Philosophie II, Werke 19, (Frankfurt am Main: Suhrkamp, 1986), 12. 
Almanya'sında filozoflar arasında Platon'a olan ilgi ve rağbet üst düzeydeydi. Örneğin Fichte $^{15}$ ve Arthur Schopenhauer ${ }^{16}$ Platon'u kendi öncülleri arasında görmekteydiler. Bu vesileyle Martin Luther'in Augustinci ve bu sebepten bir nevi neo-Platoncu olduğunu hatırlatmak yerinde olur.

\section{Törellik: Protestan İcadı}

Hegel ne hukukun ne de ahlakın yek başına var olamayacağını inanır. Hukuk ve ahlak; sadece her ikisinin sentezi olan kapsayıcı törellik yoluyla varlık kazanabilir. ${ }^{17}$ Protestanlıktan Katolikliğe olan geçişleri durdurmak için de Hegel törelliğe sarılır:

"Son zamanlarda birçok Protestan Katolik oldu. Bunu yapmalarının sebebi iç yaşantılarını fakirleşmiş olarak bulmaları ve sağlam bir otoriteye sarılma istekleriydi" . ${ }^{18}$

Çözüm ise törelliktir:

“Sübjektif ve objektif kendinde ve kendisi için var olan iyinin birliği törelliktir. Törellikte meydana gelen uzlaşma kavramla uyumludur. Ahlak, sübjektif bağlamda genel olarak iradenin formudur. Törellik ise iradenin yalnızca sübjektif formu ve öz-belirlenimi değildir, törellik aynı zamanda iradenin kavramını, yani özgürlüğü içerir.”19

Tablo 3: Ahlak - Törellik Kıyası

\begin{tabular}{|c|c|c|}
\hline Ahlak & \multicolumn{2}{|c|}{ Törellik $^{20}$} \\
\hline Sübjektiflik & Objektiflik & Birlik \\
\hline Sübjektif iyi & Objektif iyi & Birlik \\
\hline Olmalı & Zorunluluk & Birlik \\
\hline Bireysel, yalnız & Genel, hepsi & Birlik \\
\hline Sübjektif form ve iradenin & İradenin kavramı, özgürlüğü & Birlik \\
\hline
\end{tabular}

15 Fichte, Religionslehre, 424, 470.

16 Arthur Schopenhauer, Parerga und Paralipomena, (Frankfurt: Suhrkamp Taschenbuch: 1986), 63.

17 Hegel, Philosophie des Rechts Die Vorlesung von 1819/20 in einer Nachschrift, Herausgegeben von Dieter Henrich, (Frankfurt: Suhrkamp, 1983), 121.

18 Grundlinien der Philosophie des Rechts, 291. Tercüme anlam tercümesi metodu çerçevesinde serbest bir tarzda yapılmıştır. Nisbet, din değiştiren romantiklerin ana motivasyonlarının doğa ve sosyal hayatı kutsallıktan arındırmak istemeyişleri ile Fransız devriminin ideallerini kurumsallık ve otoriteye dayalı iman için inkâr etmek isteyişlerine bağlar bk. Hegel, G. W. F. Elements of the Philosophy of Right, 435.

19 Hegel, Grundlinien der Philosophie des Rechts, 291-292. Tercümede serbest bir tarz benimsenmiştir. Buradaki esas amacımız zor olan metni kolay bir şekilde sunmaktır.

20 Hegelyen törellik hukuk ve ahlakı kapsar. Ancak bu olgular bu yazıda detaylıca ele alınmamaktadır. Bu nedenle tablo daha çok makalenin ana teması ile ilgilidir. 


\section{öz-belirlenimi}

Netice itibariyle Hegel törelliği bir Protestan otoritesi olarak icat etmektedir. Onun teori ve praksis arasında ön gördügü uyum da bu Protestan icadı olan törelliğe hizmet eder. “Adem' in Havva'ya dediği gibi: Sen etimden et, kemiğimden kemiksin." ${ }^{21}$ Protestan teori bu nedenden Protestan Pratik ile uyum halindedir. Bu noktada, Protestan ilke ruh-hakikat birliği ve törelliğin kendini gerçekleştirmek dışında bir alternatifleri yoktur.

Törelliğin momentleri olan aile, sivil toplum ve devletin hepsi Protestan icadı olmak yönünde değerlendirmeye tabi tutulmak zorunda olsa bile, öne çıan esas unsur aile ve sivil toplumdan ziyade devlettir. Bu vesileyle Hegel'in sivil toplum ve devlet arasında yapmış olduğu meşhur ayrımın da törellik içerisinde olduğuna dikkat çekmek gerekir. Törellik tam anlamiyla sadece Protestan devlette vardır. Bu durumda Protestan devlet Protestan ilke ruhhakikat birliği ile mutabakat halindeki kavram-obje birliğini temsil eder. ${ }^{22}$ Hegel nesneyi kavramsallaştırdığı gibi kavramı da nesnelleştirir. Protestan olmayan devletler ise buna karşın kavram ve nesne arasında tam anlamda bir uyuma varamamaktadırlar. Hegel bunun dışında bazı dinsel grupların tam anlamıyla törellik içerisinde olamadıklarına işaret eder. Yukarıda değindiğimiz gibi o, sivil toplumu devletten ayırır. Böyle yaparak, Hegel devleti sivil topluma indirgememeye çalışır. Quaker, Anabaptist, Mennonites ve kiniklerin bourgeois olduklarına, ama citoyen olamadıklarını düşünür. Bu sebepten onlar sivil toplum üyeleri iken devletin üyeleri değildirler ve bu nedenden onlar devlet de kuramazlar. ${ }^{23}$

Hegel açısından devlet kuramama dinsel, ekonomik ve askerlik hizmetine karşı olan tutum gibi birçok motif nedeniyle olabilir. Hegel bu konuda İsa; Atina'da Diogenes; Roma' da Persius ve Juvenal'ın ekonomiye karşı olan tutumlarına dikkat çeker. Hegel onların serveti yasakladıklarına değinir. ${ }^{24}$ Öyle görünüyor ki Hegel, İsa'nın cemaatini, deyim yerindeyse, bir nevi sosyalist bir topluluk olarak algılamaktadır. Voltaire de ilk dönem Hristiyanların farklı oluşuna işaret eder ve onlara en çok benzeyen grubun Quakerlar

21 Grundlinien der Philosophie des Rechts, 47.

22 Phänomenologie des Geistes, Werke 3, 2. Aufl., (Frankfurt am Main, Suhrkamp, 1989), 74; Michael Inwood, A Hegel Dictionary, Oxford UK, The Blackwell Philosophers Dictionary 1999), 299; Beatrice Longuenesse, Hegel's Critique of Metaphysics, translated by Nicole J. Simek, (Cambridge University Press, 2007), 167.

23 Ludwig Siep, Der Staat als irdischer Gott, (Tübingen: Mohr Siebeck, 2015), 174.

24 Hegel, Vorlesungen über die Geschichte der Philosophie II, Werke 19, (Frankfurt am Main, Suhrkamp, 1986), 109110; Vorlesungen über Naturrecht und Staatswissenschaft Heidelberg 1817/18 mit Nachträgen aus der Vorlesung 1818/19 Nachgeschrieben von P. Wannenmann, Herausgegeben von C. Becker, W. Bonsiepen, A. GethmannSiefert, F. Hogemann, W. Jaeschke, Ch. Jamme, H.-Ch. Lucas, K. R. Meist, H. Schneider mit einer Einleitung von O. Pöggeler, Band 1, (Hamburg: Felix Meiner Verlag, 1983), 114-115. 
olduğuna değinir. ${ }^{25}$ Hegel, ekonominin Protestan icadı olan sivil toplumun işlevi olduğu görüşünde olmanın yanı sıra İsa'nın sivil toplum ve devleti henüz ayırmadığını düşünür. Yine de Hegel, İsa'nın Hristiyan devletinin öncüsü olduğu kanaatindedir ve buna göre İsa tarihteki Hristiyan devletlerin gerçek kurucusu olmaktadır.

\title{
2. Devlet Reformunun Temeli: Din Reformu
}

Hegel nezdinde politik reformun mahiyeti ve ana nedenine değinmeden önce, devletin temelini ele almamız gerekmektedir. Hegel'in devletinin anayasa, kültür, ulusal tin, zaman tini, ordu, yönetici, sanat, yasama gibi zorunlu üyeleri vardır. Bununla birlikte Hegel devletin merkezi kurucu unsuru olarak dini ön plana çıkarır. $\mathrm{O}$, bunun dışında dine devlet reform konusunda da temas eder. O halde din hem devletin kendisinin hem de devlet reformunun kurucu unsuru olmaktadır. Buna göre din devleti kurar iken din reformu ise devleti reformize etmektedir. Netice itibariyle devlet din ilkesini değil, aksine din devletin ilkesini belirlemektedir.

Hegel'e göre tanım hakikate tekabül eder. Bu sebepten Hegel için bir topluluk hakikatini yalnızca kendi tanımı -ki bu dindir- yoluyla öğrenebilir. Hegel dini Tanrı hakkında bilgi olarak tanımlar. O halde potansiyel halde olan bir toplumu bilfiil devlet haline dönüştüren toplumsal Tanrı bilgisidir. Devletin tanımı, yani hakikati bu durumda ulus dinidir, yani toplumsal Tanrı bilgisidir:

\author{
Hakikat $=$ tanım \\ $\downarrow$ \\ Ulusun tanımı $=$ din \\ $\downarrow$ \\ Dinin tanımı $=$ Tanrı bilgisi
}

Devletin tanımı $=$ ulusun dini, ulusun Tanrı bilgisi

Hegel bunun yanı sıra devletler arasında derecelendirmeye gider. Bir devlet ne kadar ruhsal ise o devlet o kadar iyidir. Aynı şekilde bir devlet ne kadar doğaya dayanırsa o devlet o kadar kötüdür. Bu sebepten bir devlet ne kadar doğa ile ilintili bir dine dayanırsa o devlet o kadar maddeye dayalı olurken bir devlet ne kadar ne kadar ruha dayanırsa o devletin de

25 Voltaire, Felsefe Ansiklopedisi I, çev. Lütfi Ay (İstanbul: Milli Eğitim Bakanlığı Yayınları, 1995), 386. 
dini o kadar ruhsaldır. Daha iyi bir Tanrı düşüncesine sahip olmak demek daha iyi bir devlete sahip olmak anlamina gelir: ${ }^{26}$

$$
\begin{gathered}
\text { İyi din = daha çok ruhsal Tanrı bilgisi } \\
\downarrow \\
\text { İyi devlet } \\
\text { Veya: }
\end{gathered}
$$

Kötü din: daha çok maddesel Tanrı bilgisi

\section{$\downarrow$}

Kötü devlet

Hegel en iyi devletin Hristiyan devleti olduğu kanaatindedir zira Hristiyanlığın tanımı tindir, kavramdır, mutlak tin ve sonlu tin arasındaki birliktir. Hristiyanlık dairesi içeresinde ise tin-hakikat uyumu bağlamında en üstün dereceye sahiptir. Daha çok tinsellik daha çok hakikat anlamına gelir ve aynı şekilde daha çok hakikat daha çok tinsellik anlamına gelir. Öyle görünüyor ki Hegel Protestan ilke tin-hakikat birliğini Protestanlığın tanımı olarak addetmektedir. Protestan devlet bu açıdan en iyi devlettir Hristiyanlık içerisinde. En iyi devlet ayrıca en tanrısal devlet anlamına gelir. Hegel için devlet tanrısal bir ide, kavramdır ${ }^{27}$ ve devletin tanrısallık derecesi dinin tanrısallık derecesine dayanır. Hegel aynı zamanda devletin dünyeviliğine atıfta bulunur ve bu nedenden daha iyi bir devlet daha dünyevi bir dindir. Protestan devlet bu durumda Hristiyan ilke ile tamamiyla uyum halindedir: daha çok tinsellik daha çok tanrısallık, dünyevilik ve tanrısallık-dünyevilik birliği demektir. Bu sebepten kanunlar hem Tanrı' dan ${ }^{28}$ hem de insandan neşet ederler. ${ }^{29}$

Sonuçta yukarda gösterdiğimiz gibi Hegel din ve devleti birbirlerinden ayrı bir biçimde algılamaz. Bu ayrıca dinsel ve politik reform için de söz konusudur zira yeni dinsel bir anlayış devlet reformu anlamina gelmekte ve politik reform din reformu gerektirmektedir. Bu durumda din ve devlet birbirileriyle sıkı bir biçimde bağımlıdırlar ve bunun sonucu olarak Protestan din ve devletin formu farklı olmaktadır. Protestan devleti

26 Hegel, Vorlesungen über die Philosophie der Religion I, Werke 16, 2. Aufl., (Frankfurt am Main: Suhrkamp, 1990), 237.

27 Philosophie des Rechts nach der Vorlesungsnachschrift K.G.v. Griesheims 1824/1825, Georg Wilhelm Friedrich Hegel Vorlesungen über Rechtsphilosophie 1818-1831, Edition und Kommentar in sechs Bänden von Karl-Heinz Ilting, Vierter Band, (Stuttgart-Bad Cannstatt: frommann-holzboog, 1974), 632; Vorlesungen über die Philosophie der Geschichte, 57.

28 Vorlesungen über die Philosophie der Religion I, Werke 16, 2. Aufl., (Frankfurt am Main, Suhrkamp. 1990), 237; Vorlesungen über die Philosophie der Religion, Teil 1, Einleitung. Der Begriff der Religion, Neue herausgegen von Walter Jäschke (Hamburg, Felix Meiner, 1993), 361.

29 Hegel, Grundlinien der Philosophie des Rechts, 16. 
şekillendiren Protestan ilkedir. Bu vesileyle reform ile ilintili bir başka bir konuyu gündeme getirmek yerinde olacaktır. Kanaatimizce Hegel için sanat ve felsefede durum devlette olduğu gibi- dinsel reform gerektirmektedir. Mutlak ruhun din ile birlikte diğer iki şubesi sanat ve felsefedir. Hegel diyor ki, devlet olmak isteyen bir ulusun mutlak tinin şubeleri olan sanat, din ve felsefeye sahip olması gerekir. ${ }^{30}$ Bunun yanı sıra sanat ve din kendilerini yalnızca devlette gerçekleştirebilirler. ${ }^{31}$ Hegel, Tanrı'yı sanat, din ve felsefenin konusu olarak lanse eder. Sanat ve felsefe dinden neşet etmekte ve Tanrı kavramı sanat ve felsefeye din tarafından verilmektedir. Bu bağlamda devletin yanı sıra sanat ve felsefe de dinden neşet etmektedirler. ${ }^{32} \mathrm{Bu}$ perspektiften şu neticeyi çıkarıyoruz: Hegelyen sanat ve felsefede dinsel reform gerektirmekte ve reformize edilmiş sanat ve felsefe gerçekliğini yalnızca reformize edilmiş devlette kazanabilir. ${ }^{33}$

\section{Protestan İlke: Tin ve Hakikat Birliği}

Protestanlığın ayırt edici özellikleri kendi doğasında bulunan hasletleridir. Bununla birlikte bu vesileyle Hegel'in derecelendirme yöntemine atıfta bulunmada yarar vardır. Her ne kadar bir unsur bir öğretinin özünde olsa dahi, bu onun diğer öğretilerde tamamiyla olmadıkları anlamına gelmemektedir. Buna göre Protestan ilke her ne kadar diğer dinlerin özünde yer alan bir öğreti değilse de onun etkileri belli bir noktaya kadar diğer dinlerde mevcut olabilir. Hegelyen tin-hakikat birliği Protestanlığın temelinde yer alırken Katoliklikte bu ilkenin etkileri bulunabilir her ne kadar özünde olmasa bile.

Hegel Protestan'ın Tanrı'ya içsel ve kalpten dua ve ibadet ettiğine ve bu nedenden Tanrı'nın dışsal bir şey olarak algılanmadı̆̆ını ifade eder. Tanrı tindedir, ${ }^{34}$ zevktedir, dışsallığın kaldırılmasındadır, ${ }^{35}$ evdedir dışarda değil. Karl Marks da Hegel hakkında yazmış olduğu bir yazısında Luther'in dinselliği insanın içselliği haline getirerek insanı

30 Hegel, Vorlesungen über Naturrecht und Staatswissenschaft Heidelberg 1817/18 mit Nachträgen aus der Vorlesung 1818/19 Nachgeschrieben von P. Wannenmann, 246.

31 Hegel, Vorlesungen über die Philosophie der Geschichte, 73- 74.

32 Naturrecht und Staatswissenschaft nach der Vorlesungsnachschrift von C. G. Homeyer 1818/1819, 292-293; Hegel, Enzyklopädie der philosophischen Wissenschaften im Grundrisse 1830, Dritter Teil, 353; Hegel, Vorlesungen über die Philosophie der Religion I, 236; Vorlesungen über die Philosophie der Geschichte, 70-73.

33 Hegel, Vorlesungen über die Philosophie der Geschichte, 73.

34 Hegel, Vorlesungen über die Geschichte der Philosophie III, Werke 20, (Frankfurt am Main, Suhrkamp, 1986), 63; Enzyklopädie der philosophischen Wissenschaften im Grundrisse 1830, Dritter Teil, 357.

35 Hegel, Enzyklopädie der philosophischen Wissenschaften 1827, Gesammelte Werke 19, Hrsg. Wolfgang Bonsiepen und Hans Christian Lucas, Rheinisch-Westfälische Akademie der Wissenschaften, Hamburg: Felix Meiner Verlag, 1989), 396. 
dinsel dışsallıktan kurtardığına işaret eder. ${ }^{36}$ Tin mutlak tin ve sonlu tinin birliği olmasına rağmen yine de Hegel Tanrı'yı sonlu tinden ayırır. Mutlak tin ve sonlu tinin birliği onların ayrımında yatar. Hegel devam ediyor: Sonlu tin Tanrı'ya tin olarak sahip olmalı ki ${ }^{37}$ böylece tinsel Tanrı'nın içselliği kendini sonlu tinde gerçekleştirsin. ${ }^{38}$ Mutlak hakikat bağlamında insan önünde bulduğu dışsal mevcudiyet ile başlamaz, aksine özü itibariyle tinsellik olan içsellik ile başlar. Bu durumda mutlak bilgiye ulaşılabilir çünkü mutlak bilgi tinselliğe dayanir. ${ }^{39}$

Tanrı içsel olarak düşünüldüğü için Hegel düşünceyi Protestanlığın hakemi olarak tespit eder. Buna karşın Katoliklik Tanrı'yı dışsal ve ayrık olarak idrak ettiği için Katolikliğin hakemi olarak idraki belirler. ${ }^{40} \mathrm{Bu}$ nedenden din, devlet, anayasa, yürütme, dünya tini gibi tinsel ideler Katoliklik tarafından idrak olguları olarak algılanmaktadır. Hegel dışsal Katolik idrak bakışlı Tanrı konusunu daha fazla olgu ile de ilişkilendirir: Katolik kilisesi dışsal kiliseler inşa eder ve papalığa, keşişlere vs. ye sahiptir. Bu ise dolayımız şimdiki zamana tekabül eder, yoksa gerçek bilfiil zamana değil. Bilindiği gibi Hegel felsefesinde dolayımsızlık bilfiil gerçeklik kazanmak için kaldırıp-içerme gerektirir. Bir Katolik şimdide mevcudiyetini Kenan'da, Nasıra'da zeytin dağında arar. Bunun yanı sıra Mesih Katolik kilisesinde mazidedir, o anılarda yaşar ve ümitler onunla ilişkilendirilir. Hegel bu olguları hem Katolik dişsal zamansallık hem de mekansallık çerçevesinde ele alır. ${ }^{41}$ Protestanlıkta ise Tanrı'nın'2 yanı sıra Mesih'in kalpte kutsandığına ve bu nedenden onların kalpte hem zamansallık hem de mekansallık açılarından şimdide mevcut olduklarına temas eder. Zamansallık bağlamında hatırlatılması gereken bir durum vardır, o da Hegel nazarında geniş zamana şimdilik üzerinden geçilmesidir. Buna göre Protestan'ın gerçek şimdilik formuna sahip olması onun geniş zaman formuna sahip olması anlamına geliyor olmalıdır Hegelyen felsefede. Hegel özellikle halkın kitabı olan Luther'in İncil tercümesine atıfta bulunur ve bu hususta da yine Katolikliği itham eder: Her ne kadar Katoliklerin onlarca dua

36 Karl Marx, Zur Kritik der Hegelschen Rechtsphilosophie. Einleitung, Karl Marx Friedrich Engels Werke, Band 1, (Berlin: Dietz Verlag, 1972), 386.

37 Hegel, Enzyklopädie der philosophischen Wissenschaften im Grundrisse 1830, Dritter Teil, 301-302.

38 Martin Luther, An den christlichen Adel deutscher Nation, An der christlichen Adel deutscher Nation, Von der Freiheit eines Christenmenschen, Sendbrief vom Dolmetschen, Hrsg. von Ernst Kähler, (Stuttgart: Reclam, 1982), 19

39 Hegel, Phänomenologie des Geistes, 582

40 Hegel, Vorlesungen über die Geschichte der Philosophie III, Werke 20, (Frankfurt: Suhrkamp, 1986), 63.

41 Hegel, Vorlesungen über die Geschichte der Philosophie II, Werke 19, (Frankfurt, Suhrkamp, 1986), 597; Enzyklopädie der philosophischen Wissenschaften im Grundrisse 1830, Dritter Teil, 552

42 Hegel, Enzyklopädie der philosophischen Wissenschaften 1827, 396. 
kitapları olsa dahi, onların halkın kitabı olarak atfedebilecekleri yaygın bir öğretim eserleri yoktur. ${ }^{43}$ Dini otorite konusunda ise Hegel Protestanlık için tinin tanıklığını ve İncili, Katoliklik için ise kiliseyi belirler. Protestan otorite bizatihi içsel iken Katolik otorite ise dışsaldır. Luther'in kendisi de kilise otoritesinin papalık otoritesi oluşturduğuna temas eder. $^{44}$

En sonda ise Hegel'in laik-rahip ilişkisi konusunda düşüncelerine değinmek istiyoruz. Karl Marks, Luther'in laikleri rahip yapmasından nedeniyle rahipleri laik kişilere dönüştürdüğünü belirtir. ${ }^{45}$ Hegel de benzer biçimde Katolikliğin aksine Protestanlıkta laik ve rahip arasında özlü bir ayrım görmez:46 rahip evliliği yoluyla tarihsel olarak laik-rahip ikilemi aşıldı. Rahibin laik gibi vahyi yoktur. O halde tanrısallık ve insanilik arasında artık bir ayrım kalmamıştır. ${ }^{47}$

Tablo 4: Protestanlık - Katoliklik Kıyası

\begin{tabular}{|c|c|c|}
\hline & Protestanlık & Katoliklik \\
\hline Tanrı'nın Hakikati & Tin'de & Tin $\leftrightarrow$ hakikat \\
\hline Hakem & Düşünce & İdrak \\
\hline Tanrı & İçsellik/kalpte, zevkte, ruhta & Dişsal/Kenan'da \\
\hline Tanrı & Şimdiki zaman (geniş) & Geçmiş zaman \\
\hline Isa & Şimdiki zaman (geniş) & Geçmiş, dolaysıyla hatıralarda \\
\hline Kutsal yerlerin & Şimdiki zaman (geniş) & Dolayımsız şimdilik \\
mekânı & & \\
\hline
\end{tabular}

43 Hegel, Vorlesungen über die Philosophie der Geschichte, 498-499; Nachschrift Karl Hegel Anhang 3, Die Philosophie der Geschichte, Vorlesungsmitschrift Heimann (Winter 1830/1831), Hrsg. Klaus Vieweg, jena-sophia, Studien und Editionen zum deutschen Idealismus und zur Frühromantik, Herausgegeben von Christoph Jamme und Klaus Vieweg, Abteilung I - Editionen Band 3, (Münschen: Wilhelm Fink Verlag, 2005), 218

44 Luther, An den christlichen Adel deutscher Nation, 13.

45 Marx, "Zur Kritik der Hegelschen Rechtsphilosophie“, 386.

46 Karl Rosenkranz, Ueber Schelling und Hegel Ein Sendschreiben an Pierre Leroux, (Königsberg: Gebrüder Bornträger, 1843), 50.

47 Hegel, Vorlesungen über die Philosophie der Geschichte, 95-496, 503; Vorlesungen über die Philosophie der Religion I, 238-239. 


\begin{tabular}{|c|c|c|}
\hline $\begin{array}{c}\text { Kutsal yerlerin } \\
\text { Zamanı }\end{array}$ & Şimdiki zaman (geniş) & Geçmiş zaman \\
\hline Otorite & İncil, ruhun tanıklı̆̆ & Kilise \\
\hline $\begin{array}{c}\text { Herkes için } \\
\text { öğretim }\end{array}$ & Halkın kitabı (Luther'in İncil \\
tercümesi) & - \\
\hline $\begin{array}{c}\text { Rahip ve rahip } \\
\text { olmayan (laik) }\end{array}$ & Birlik & Farklılık \\
\hline
\end{tabular}

Bu bölümü Hegel'in içsellik- dışsallık ikilemi ile ilgili bazı izahlar ile bitirmek istiyoruz. Hegel Cermen dünya ve Cermen olmayan dünyayı; sömürgeci ve sömürülen yurtları çatıştırdığı gibi Protestan içsellik ve Katolik dışsallığı çatıştırdığı gibi sürekli çatıştırmaktadır. O, konuya Protestanlığın içselliğine vurgu yaparak konunun önemini artırmaya çalışır gibi görünmektedir. Ayrıca Hegel'in burada bahsettiği dışsallığın gerçek bir hakikati yoktur. Dolayısıyla birinci ünitede verilen tabloda belirtilen dışsallık, Katolik dışsallık ile tamamıyla uyuşmamaktadır. Hatta tabloda belirtilen dışsallığa tam anlamıyla intibak eden dişsallık Protestan dışsallıktır zira gerçek içsellik gerçek dişsallık anlamına gelir. Bu yorumumuza dayanarak biz Katolik dişsallığın Protestan dışsallıktan daha az olduğunu işaret etmekteyiz. Bunun dışında içsellik konusunda Luther'in Hegel ile benzer bir bakış açısına sahip olduğuna değinilmeli ve muhtemelen Hegel bu konuda Luther'den etkilenmiş olmalıdır. Luther'e göre bir şeyleri iman ile tanıyıp imana yerleştirirsek onlar içsel olmaktadır ve bunun tersi ise hiçbir şeye sahip olmamaktır. ${ }^{48}$ Protestan içsellik ve Katolik dışsallığın siyasete yansımalar vardır. Hakiki bir din-devlet birliği yalnızca Protestan devlette bulunmaktadir ${ }^{49}$

\section{Protestan Devlet Katolik Devlete Karş1}

Hegel'in Protestan ilkesi olan tin-hakikat birliğinden dört ana sonuç çıkarmaktayız ve bunların hepsi bir şekilde Katoliklik ile ilişkilidirler. Bu bağamda yine Hegel'in

48 Martin Luther, Von der Freiheit eines Christenmenschen, An der christlichen Adel deutscher Nation Von der Freiheit eines Christenmenschen Sendbrief vom Dolmetschen, Hrsg. von Ernst Kähler (Stuttgart: Reclam, 1982), 130131.

49 Hegel, Vorlesungen über die Philosophie der Religion I, Werke 16, 2. Aufl., (Frankfurt: Suhrkamp, 1990), 238. 
derecelendirme metoduna değinmek gerekir. Bu yöntemin sonucu olarak Protestan devlet dışındaki devletler bu sonuçların unsurlarına sahip olabilirler, her ne kadar Protestan devlet kadar olmasa bile.

i. İçsel-Tinsel Protestan Devlet - Dışsal Katolik Devlet: Hegel Protestan devletin tinsel olduğunu düşünür zira Protestan tanrı içsel olarak bilinir. Buna karşın Katolik devlet dışsaldır çünkü Katolik tanrı dışsal olarak idrak edilir. Bunu sonucu olarak Protestan devlet sorunlarını içsel olarak çözerken Katolik devlet ise dişsal olarak çözümlemektedir. Hegel Latin Katolik devletlerin son otuz yıllarının sonucunda bunun yaşandığına işaret eder. ${ }^{50} \mathrm{Bu}$ ülkelerin yurttaşları sorunları dışsal olarak algılarlar çünkü dışsal tanrı algısı yüzünden devletlerini kendilerinden uzaklaştırmaktadırlar. Sorunlar dışardadır, evde, içerde değil ve dışardaki sorunları çözümlemek çok daha zordur. Bu ülkelerde dolayısıyla çatışma hüküm sürmüştür. Bu ana düşünce çerçevesinde Hegel Katolik güney Amerika devletleri ve Fransız ihtilali hakkında muhteşem bir yorumda bulunur: Din reformu olmadan bu ülkelerde meydana gelen kanlı devrimler çatışmadan ari olamayacaktır. ${ }^{51}$ Yine de Hegel'in bu tutumuna istinaden onun tüm devrimlere olumsuz olarak yaklaştığı söylenemez. $\mathrm{O}$ kesinlikle makul politik değişimlere karşı değildir ve bu konuda Platon'dan da etkilenmiş gözükmektedir. Hegel Platon'u anlatırken onun, eğer politik dönüşümler genel ortak bir kanaat ile gerçekleşmesi halinde devrimlerin zorbalık ile gelişmeyeceği, fikrine atıf yapar. ${ }^{52}$ Yukarda Hegel nazarında Protestan icadı törelliğin kapsayıcı işlevine değinilmektedir. Ayrıca aşağıda göreceğimiz gibi Hegel için kapsamlılık Protestan devletin karakteristiğinde bulunmaktadır. Protestan tininde olduğu gibi politik yenilikler tinden taşmalı zira hakikat tinden taşar. Bu sebepten Hegel'e göre Protestan devletlerde politik reformlar dinsel reformlar ile meydana gelmektedir. Netice itibariyle politik devrim dinsel devrimi gerektirir. Tüm bu durumlarda Hegel Protestan tinin devlet ile uyumlu olduğunu düşünür. Protestan devletin yasaları bu neden hem tanrisal hem de ussaldırlar. ${ }^{53}$ Protestan din ve devlet sonuçta birbirlerine karşıt bir biçimde çatışma halinde değildirler.

\footnotetext{
50 Philosophie des Rechts nach der Vorlesungsnachschrift K.G.v. Griesheims 1824/1825, 650-651; Ludwig Siep, Der Staat als irdischer Gott, 169, 176-177.

51 Hegel, Vorlesungen über die Philosophie der Geschichte, 535; Enzyklopädie der philosophischen Wissenschaften im Grundrisse 1830, Dritter Teil, 552; Fiala A. (February 2006). The Vanity of Temporal Things: Hegel and the Ethics of War, Studies in The History of Ethics, 14-16.

52 Hegel, Vorlesungen über die Geschichte der Philosophie II, 113.

53 Hegel, Vorlesungen über die Geschichte der Philosophie I, 238.
} 
ii. Laik-Protestan Devlet - Laik Olmayan Katolik Devlet: Hegel Katolik devletin aksine Protestan devleti laik olarak addeder. Bu nedenle klerik sınıf Katolikliğin aksine Protestan devlette etkin değildir. Hegel'in rahip ve laik arasında gözettiği birlik, politik yönetimi göksel ve yersel olarak bölmemektedir. Bu bakış açısından o papayı Katolik imparatora paralel bir yönetici olarak görmektedir. Hegel'e göre laik devlet olmak dinin devlete olan etkisini yok etmemektedir. Din ve devlet arasındaki hakiki birlik sadece Protestan devlette gerçekleşmektedir zira Protestan tin laikliği tanrısallıktan ayırmamaktadır. Bununla uyumlu bir biçimde Hegel Protestan devletin Katolik devletten daha kutsal olduğu kanaatini taşır.

iii. Ulus Devlet - Katolik Imparatorluk: Hegel, Luther'in çağrısına prenslerin derhal dikkatini çektiklerine atıfta bulunur. Prensler, merkezi Katolik sisteme bağl1lıktan dolayı şikâyetçiydiler. Kaçınılmaz bir biçimde bölgesel karşı çıkışlarda artmalar meydana gelmişti. ${ }^{54}$ Hegel Katolikliğin aslında ikili bir yönetici olgusuna sahip oluşuna işaret eder: Papa ve imparator. Öte yandan Protestan yönetici kraldır ve papaya benzer bir şekilde ona paralel olan göksel bir yönetici yoktur. Hegel bu nedenden Prusya yöneticisini kral, Avusturya yöneticisini ise imparator olarak görmektedir. İmparatorluk toplama bir kompozisyon iken ulus ise bizatihi içsel hakiki bir totalitedir. Hegel bu sebepten asli olmayan bir ulusun istediği zaman sözleşme ile bağımlı olduğu imparatorluktan çıkabileceğini ileri sürer. Sözleşme ile bağımlılık dışsal bir taahhüttür. Hakiki ulus bir sözleşme ile ülkesine bağımlı değildir. Dolayısıyla ulusal yönetici kendi halkıyla sözleşme yapmaz. Katolik bir imparator o halde kendi ulusunun gerçek yöneticisi iken sözleşme ile bağımlı olanların değildir. Bu maddede en son Hegelyen ulus devlete uluslararası ilişkiler açısından değinmek istiyoruz. Abbé de Saint-Pierre, Immanuel Kant ve Friedrich Schiller gibi dünya yurttaşlarının aksine Hegel kesinkes ülke yurttaşıydı. Katolik öğretiye saldırdığından dolayı Katolik evrenselciliğe sarılması imkân dâhilinde değildi. Hegel'in ülkelerarası birleşmelere onay verdiği ise doğrudur. Bununla birlikte ülkelerarası birleşmelere olan yaklaşımı devlet merkezli bir yaklaşım nedeniyledir, yoksa uluslararası barış perspektifinden dolayı değil. Bu nedenle devletlerin birleşmesi, devletlerin kaldırılması yoluyla yeni bir devlet anlamına gelmektedir.

54 Hegel, Vorlesungen über die Philosophie der Geschichte, 515-519; Karl Rosenkranz, Erläuterungen zu Hegel's Enzyklopädie der philosophischen Wissenschaften, Philosophische Bibliothek oder Sammlung der Hauptwerke der Philosophie alter und neuer Zeit, Unter Mitwirkung namhafter Gelehrten herausgegeben, beziehungsweise übersetzt, erläutert und mit Lebensbeschreibungen versehen von J. H. V. Kirchmann., Vierunddreissigster Band, (Berlin: Verlag von L. Heimann, 1870), 113-114. 
iv. Güvenilir Protestan Devlet - Güvensiz Katolik Devlet: Törellik ile uyumlu bir biçimde Hegel'in Protestan tinselliği tüm yaşamı kapsar. Protestan devlette güven hüküm sürer ve herkes birbirine güvenir. Hegel her bir Protestan yurttaşın tinsel bütünlügün üyesi olduğu kanaatindedir. Buna karşın o, Katolik tin ve devletin bu tarz bir güveni tesis edememesi nedeniyle suçlar ve bunun sonucu olarak Katolik devlette güvensizlik hüküm sürmektedir. O halde Katolik yurttaşlar bir araya getirilmiş bütünün parçalarıdırlar. Hegel Katolik güvensizliğin hakiki evrensel törelliği engellediğini düşünür. Sonuç itibariyle Katolik yurttaş genel toplum içeresinde yalnızdır. Bunu dışında Hegel devlet ve toplum arasında da Katolik güvensizliğin meydana geldiğini iler sürer: Katolik Fransa' da hukuk ve anayasaya karşı olan yaklaşımlardan dolayı hükümet ve toplum arasındaki anlaşmazlık güvensizlik ile neticelendi. Katolik devlette dünyevi meseleler güven yerine daha çok zorbalık ve boyun eğdirme yoluyla yerine getirmektedir zira Katolik dünya tinsel-dinsel yaşamı laik devlet ile yeterince uyumlu hale getirememektedir. $\mathrm{Bu}$ şu anlama gelmektedir: İçsel ve tinsel olan güvenilirdir, dışsal olan ise düşmandır. Hegel ayrıca güvenilir olmayan dışsallığı Katolik anayasasına göre acil yardım olarak değerlendirir. O bununla, Katolik anayasasına yalnızca bireysel ve dişsal olarak başvurulduğu takdirde Katolik anayasasının mevcut olduğunu da söylemek istemektedir. Buna göre Katolik anayasa her daim ulaşılabilir değildir, dolayısıyla o, kapsayıcılıktan yoksundur. ${ }^{55}$ Protestan anayasa ise buna karşın kapsayıcıdır. Hakikat tamamina ait olandır. ${ }^{56}$

Tablo 5: Protestan Devlet - Katolik Devlet Kiyası

\begin{tabular}{|c|c|c|}
\hline & Protestanlık & Katoliklik \\
\hline Devlet & Tin'de & Tin Dişında \\
\hline $\begin{array}{c}\text { Anayasa, hukuk, } \\
\text { törellik }\end{array}$ & Güven/ kapsamlı & $\begin{array}{c}\text { Güvensizlik/zorlama- boyun } \\
\text { eğdirme/ bireysel/ } \\
\text { dişsal/aciliyet }\end{array}$ \\
\hline Devletin formu & Devlet & İmparatorluk \\
\hline
\end{tabular}

55 Hegel, Vorlesungen über die Philosophie der Geschichte, 112.

56 Hegel, Phänomenologie des Geistes, 24. 


\begin{tabular}{|c|c|c|}
\hline Yönetici & Kral & İmparator ve papa \\
\hline Sözleşme & - & Asli olmayan toplumlar ile \\
\hline Politik devrimler & İçsel, din reformu & Dişsal/ şiddetle \\
\hline $\begin{array}{c}\text { Politik açıdan din- } \\
\text { devlet ilişkileri }\end{array}$ & Laik & Laik değil \\
\hline $\begin{array}{c}\text { Felsefi açıdan din-devlet } \\
\text { ilişkileri }\end{array}$ & Din-devlet birliği & Din-devlet ikilemi \\
\hline
\end{tabular}

\section{Sonuç}

Sonuç kısmına öncelikle ulaşılan bazı neticeler ile başlamak istiyoruz. Devlet ve devletin işlevi hakkında zor ve zor olduğu kadar da önemli görüşler serdeden Hegel'in devlet ve devletin 1slahı konularında dinin ne kadar büyük bir rol oynadığ gösterilmeye çalışılmıştır. Hegel'in merkeze aldığı din versiyonu, yukarda gösterildiği gibi, Katoliklik karşısındaki Protestan Hristiyanlıktır. Bununla beraber Protestanlık dışındaki din mensupları için ilgi ve merak uyandıran görüşlere yer verdiğine dikkat çekilmelidir. Şayet diyor Hegel, politik yenileşme dinsel yenileşme ile uyumlu bir biçimde ilerlemezse, o devlet yine de krizdedir, politik yenilikler hayata geçirilse bile. Mesela din demokrasiye geçit vermeden, devlet demokrasiye geçse bile, çatışmadan kaçınılamaz. Hegel; din ve devlet arasındaki bütünlüğe vurgu yaptı ve bu anlayışın aslında günümüzde de önemli bir dereceye kadar dünyanın birçok yerinde geçerli olduğu söylenebilir. Hegel din ve devlet arasındaki birliği savunarak uyumluluğa da ne kadar önem verdiğini göstermektedir. Devletin ıslahı hususunda onun vurgu yaptığı önemli vurgulardan birisi zamanın ruhu ile olan uyumdur. Buna göre asrilik zorunlu bir unsurdur ve çağdaşlaşmayan her kültür dünyayı geriden takip etmeye mahkûmdur. Veya devletin içsel ve dışsal yönleri arasında uyumu şart koşar. İki tarafı birbirleriyle uyumlu olmayan devleti Hegel problematik olarak addetmektedir.

Hegel Protestan devlet ile kanaatimizce modern devleti de kastetmektedir. Bu, bizim Hegel yorumumuza göre, Protestan olmayan ülkelerin hiçbir biçimde modern 
olamayacaklarına anlamına gelmemektedir. Olabilirler, ama bir dereceye kadar: Protestan bir devlet Katolik devletten daha moderndir ve Katolik bir devlet ise Budist devletten daha moderndir... Dünya tini hala bu Protestan devleti taşımakta ve bizim değerlendirmemize göre Hegel'in Protestan devleti bilinmeden modern devlet gerçeği ile hesaplaşılamaz. Bunun dışında onun Avrupa merkeziyetçiliği de tam olarak değerlendirmeye tabi tutulamaz. Hem modern devlet hem de Avrupa merkeziyetçilik Protestan ilke ile yakından irtibatlıdır. Avrupa merkeziyetçilik hakkında Cermen ilke ve kültür de Protestan ilkenin yanı sıra göz önünde bulundurulmalıdır:

i. Sanat, din ve felsefe birliği: Kültür

ii. Tin-hakikat birliği: Protestan İlke

iii. Tanrısallık-Dünyevilik Birliği: Cermen-Hristiyan İlke

Prensiplere dayalı kolektif yaklaşımlar bize modern devlet ve uygarlık konularında farklı yaklaşımlar sunabilir. Başka uzmanlar bu ilkelere farklı ilkeler ve öğretiler eklemelidirler. Bu noktada ilkelerin ele alınış tarzlarda önem kazanmaktadır. Örneğin bu çalışmada biz Protestan ilkeden neşet eden politik çıkarımlar ile onların hakikat ve tanımla olan bağlarını ele almaktayız. Başka çalışmalar Protestan ilkeyi farklı konu ve perspektifler ile ele alabilirler, hatta almalıdırlar da.

En sonda ise bu çalışmayı devlet, din ve felsefenin kendi aralarında ilişkileri bağlamında bazı ifadelendirmeler ile tamamlamak istiyoruz. Tartışmasız Luther Hegel'in öncülleri arasında yer almaktaydı. Aslında Hegel'i bir yönüyle Luther'in laik versiyonu olarak yansıtmak sanırım abartı olmayacaktır. Luther kitlelerin filozofuyken Hegel ise elitlerin rahibi... Bunun dışında Hegel Prusya'nın Yedi Yıl Savaşı yoluyla Protestanlığın garantisini tamamladığını belirti. ${ }^{57}$ Belki de Hegel II. Friedrich'in misyonunu felsefi olarak tamamlamaktaydı. Hegel için Hristiyanlığın zirvesi Protestanlıktır. Luther dini, Friedrich devleti Hegel ise felsefeyi temsil etmektedir. Bu teslis Hristiyan teslis ile uyumlu görünmektedir: Luther Baba, Friedrich Oğul, Hegel ise Kutsal Ruh olarak.

57 Hegel, Vorlesungen über die Philosophie der Geschichte, 519. 


\section{Kaynakça}

Fiala, Andrew. The Vanity of Temporal Things: Hegel and the Ethics of War, Studies in The History of Ethics, February 2006.

Fichte, Johann Gottlieb. Die Anweisung zum seligen Leben, oder auch die Religionslehre, Johann Gottlieb Fichtes sämmtliche Werke. Band 5, Berlin: Verlag von L. Heimann, 1845/1846.

Hegel, Georg Wilhelm Friedrich. Werke in zwanzig Bänden. Theorie-Werkausgabe (I-XX), Hrsg. von E. Moldenhauer/K. Michel. Frankfurt a.M., 1986.

Hegel, Georg Wilhelm Friedrich. Glauben und Wissen oder die Reflexionsphilosophie der Subjektivität in der Vollständigkeit ihrer Formen als Kantische, Jacobische und Fichtesche Philosophie, Jenaer Schriften, Werke 2, Frankfurt: Suhrkamp, 1986.

Hegel, Georg Wilhelm Friedrich. Phänomenologie des Geistes, Werke 3, 2. Aufl., Frankfurt: Suhrkamp, 1989.

Hegel, Georg Wilhelm Friedrich. Elements of the Philosophy of Right, edited by Allen W Wood; translated by H B Nisbet, Cambridge: Cambridge University Press, 1991.

Hegel, Georg Wilhelm Friedrich. Grundlinien der Philosophie des Rechts oder Naturrecht und Staatswissenschaft im Grundrisse, Mit Hegels eigenhändigen Notizen und den mündlichen Zusätzen, Werke 7, 2. Aufl., Frankfurt am Main: Suhrkamp, 1989.

Hegel, Georg Wilhelm Friedrich. Wissenschaft der Logik I, Werke 5, Frankfurt: Suhrkamp, 1986.

Hegel, Georg Wilhelm Friedrich. Enzyklopädie der philosophischen Wissenschaften 1827, Gesammelte Werke 19, Hrsg. Wolfgang Bonsiepen und Hans Christian Lucas, Rheinisch-Westfälische Akademie der Wissenschaften, Hamburg: Felix Meiner Verlag, 1989.

Hegel, Georg Wilhelm Friedrich. Enzyklopädie der philosophischen Wissenschaften im Grundrisse 1830, Erster Teil, Die Philosophie des Geistes Mit den mündlichen Zusätzen, Werke, Frankfurt: Suhrkamp, 1989.

Hegel, Georg Wilhelm Friedrich. Enzyklopädie der philosophischen Wissenschaften im Grundrisse 1830, Dritter Teil, Die Philosophie des Geistes Mit den mündlichen Zusätzen, Werke 10, Frankfurt: Suhrkamp, 1986.

Hegel, Georg Wilhelm Friedrich. Vorlesungen über die Philosophie der Geschichte, Werke 12, Frankfurt: Suhrkamp, 1986.

Hegel, Georg Wilhelm Friedrich. Vorlesungen über die Philosophie der Religion I, Werke 16, 2. Aufl., Frankfurt: Suhrkamp, 1990.

Hegel, Georg Wilhelm Friedrich. Vorlesungen über die Geschichte der Philosophie I, Werke 18, Frankfurt: Suhrkamp, 1986.

Hegel, Georg Wilhelm Friedrich. Vorlesungen über die Geschichte der Philosophie II, Werke 19, Frankfurt: Suhrkamp, 1986.

Hegel, Georg Wilhelm Friedrich. Vorlesungen über die Geschichte der Philosophie III, Werke 20, Frankfurt: Suhrkamp, 1986.

Hegel, Georg Wilhelm Friedrich. Vorlesungen über Naturrecht und Staatswissenschaft Heidelberg 1817/18 mit Nachträgen aus der Vorlesung 1818/19 Nachgeschrieben von P. Wannenmann, Herausgegeben von C. Becker, W. Bonsiepen, A. Gethmann-Siefert, F. Hogemann, W. Jaeschke, Ch. Jamme, H.-Ch. Lucas, K. R. Meist, H. Schneider mit einer Einleitung von O. Pöggeler, Band 1, Hamburg: Felix Meiner Verlag, 1983. 
Hegel, Georg Wilhelm Friedrich. Philosophie des Rechts Nach der Vorlesungsnachschrift H.G. Hotho 1822/1823, Georg Wilhelm Friedrich Hegel Vorlesungen über Rechtsphilosophie 1818-1831, Edition und Kommentar in sechs Bänden von Karl-Heinz Ilting, Dritter Band, Stuttgart-Bad Cannstatt: frommann-holzboog, 1974.

Hegel, Georg Wilhelm Friedrich. Philosophie des Rechts nach der Vorlesungsnachschrift K.G.v. Griesheims 1824/1825, Georg Wilhelm Friedrich Hegel Vorlesungen über Rechtsphilosophie 1818-1831, Edition und Kommentar in sechs Bänden von Karl-Heinz Ilting, Vierter Band, Stuttgart-Bad Cannstatt: frommann-holzboog, 1974.

Hegel, Georg Wilhelm Friedrich. Vorlesungen über die Philosophie der Religion, Teil 1, Einleitung. Der Begriff der Religion, Neue herausgegen von Walter Jäschke, Hamburg: Felix Meiner, 1993.

Hegel, Georg Wilhelm Friedrich. Einleitung nach der Vorlesung im Wintersemester 1818/19 in Berlin, Vorlesungen über Naturrecht und Staatswissenschaft Heidelberg 1817/18 mit Nachträgen aus der Vorlesung 1818/19 Nachgeschrieben von P. Wannenmann, Herausgegeben von C. Becker, W. Bonsiepen, A. Gethmann-Siefert, F. Hogemann, W. Jaeschke, Ch. Jamme, H.-Ch. Lucas, K. R. Meist, H. Schneider mit einer Einleitung von O. Pöggeler, Band 1, Hamburg: Felix Meiner Verlag, 1983.

Hegel, Georg Wilhelm Friedrich. Nachschrift Karl Hegel Anhang 3, Die Philosophie der Geschichte, Vorlesungsmitschrift Heimann (Winter 1830/1831), Hrsg. Klaus Vieweg, jenasophia, Studien und Editionen zum deutschen Idealismus und zur Frühromantik, Herausgegeben von Christoph Jamme und Klaus Vieweg, Abteilung I - Editionen Band 3, Münschen: Wilhelm Fink Verlag, 2005.

Hegel, Georg Wilhelm Friedrich. Briefe von und an Hegel: Band I, 1785-1812, Hamburg: Felix Meiner Verlag, 1969.

Hegel, Georg Wilhelm Friedrich. The Letters. Translated by Clark Butler and Christiane Seiler with commentary by Clark Butler, Bloomington: Indiana University Press, 1984.

Hegel, Georg Wilhelm Friedrich. Naturrecht und Staatswissenschaft nach der Vorlesungsnachschrift von C. G. Homeyer 1818/1819, Georg Wilhelm Friedrich Hegel Vorlesungen über Rechtsphilosophie 1818-1831, Edition und Kommentar in sechs Bänden von Karl-Heinz Ilting, Erster Band, Stuttgart-Bad Cannstatt, frommann-holzboog, 1973.

Inwood, Michael. A Hegel Dictionary. Oxford UK, The Blackwell Philosophers Dictionaries, 1999.

Longuenesse, Beatrice. Hegel's Critique of Metaphysics, translated by Nicole J. Simek, Cambridge University Press, 2007.

Luther, Martin. An den christlichen Adel deutscher Nation, An der christlichen Adel deutscher Nation, Von der Freiheit eines Christenmenschen, Sendbrief vom Dolmetschen, Hrsg. von Ernst Kähler, Stuttgart: Reclam, 1982.

Luther, Martin. Von der Freiheit eines Christenmenschen. An der christlichen Adel deutscher Nation, Von der Freiheit eines Christenmenschen, Sendbrief vom Dolmetschen, Hrsg. von Ernst Kähler, Stuttgart: Reclam, 1982.

Marx, Karl. Zur Kritik der Hegelschen Rechtsphilosophie. Einleitung, Karl Marx Friedrich Engels Werke, Band 1, Dietz Verlag Berlin, 1972.

Novalis. Die Christenheit oder Europa. Ein Fragment. Ludwig Tieck, Friedrich Schlegel (Hrsg.): Novalis Schriften, Bd. 1. Berlin: Reimer, 1826.

Rosenkranz, Karl. Ueber Schelling und Hegel Ein Sendschreiben an Pierre Leroux, Königsberg: Gebrüder Bornträger, 1843. 
Rosenkranz, Karl. Erläuterungen zu Hegel's Enzyklopädie der philosophischen Wissenschaften, Philosophische Bibliothek oder Sammlung der Hauptwerke der Philosophie alter und neuer Zeit, Unter Mitwirkung namhafter Gelehrten herausgegeben, beziehungsweise übersetzt, erläutert und mit Lebensbeschreibungen versehen von J. H. V. Kirchmann., Vierunddreissigster Band, Berlin, Verlag von L. Heimann, 1870.

Rosenzweig, Franz. Hegel und der Staat, Herausgegeben von Frank Lachmann, Mit einem Nachwort von Axel Honneth, Berlin: Suhrkamp Verlag, 2010.

Schnädelbach, H. Georg Wilhelm Friedrich Hegel zur Einführung, Hamburg: Junius Verlag, 2013.

Schopenhauer, A. Parerga und Paralipomena, Suhrkamp Taschenbuch: Frankfurt, 1986.

Siep, Ludwig. Der Staat als irdischer Gott, Tübingen: Mohr Siebeck, 2015.

Stepelevich, L. S. "Hegel and Roman Catholicism". Journal of the American Academy of Religion $60 / 4$ (Winter, 1992), 673-691.

Voltaire. Felsefe Ansiklopedisi I. çev. Lutfi Ay. İstanbul: Millî Eğitim Bakanlığı Yayınları, 1995. 